\title{
EVALUATION OF THE LOCAL MANUFACTURING AND BOND BEHAVIOUR OF GFRP RODS HYBRIDIZED WITH STEEL WIRES FOR CONCRETE REINFORCEMENT
}

\author{
Mamdouh Sayed Abdelbaqi* \\ Civil Engineering Department, Luxor Higher Institute of Engineering \& Technology, \\ Luxor 85834, Egypt \\ Mohaseb Ahmed Abozied \\ Civil Engineering Department, Luxor Higher Institute of Engineering \& Technology,
} Luxor 85834, Egypt

Mohamed Ahmed Saifeldeen

Civil Engineering Department, Aswan University, Egypt

Hossameldeen Mohamed

Civil Engineering Department, Aswan University, Egypt

Omar Ahmed Farghal

Civil Engineering Department, Assiut University, Egypt

\author{
Abd El Rahman Megahid Ahmed \\ Civil Engineering Department, Assiut University, Egypt \\ *Corresponding Author Email: Mamdouhalngmy2@gmail.com
}

\begin{abstract}
Steel erosion and environmental harm caused by manufacturing of steel bars, motivate engineers and material scientists to define new alternatives for the oldest material in construction. Even though, Fibre-Reinforced Polymers stands as a promising alternative, the low modulus of elasticity barriers their wide-use. Recently, hybridization of FRP with steel leads to a new type of reinforcement which can be used as a good alternative to steel rods and overcome the flaw of low modulus of elasticity of conventional FRP. Depending on the ratio of hybridization an approximately $200 \%$ increase in the modulus of elasticity with sufficient tensile strength is experimentally proved. Still, the ability of the new rods and their integration with surrounding concrete were not extensively studied in previous studies. Bonding between new rods and the surrounding concrete is a key parameter to assess the integrity of reinforced concrete components. Therefore, this paper
\end{abstract}


Evaluation of the Local Manufacturing and Bond Behaviour of GFRP Rods Hybridized with Steel Wires for Concrete Reinforcement

investigates the bonding behaviour of the new hybrid rods with concrete. The manufacturing techniques for the used hybrid rods are first presented then, the bonding between the rods and concrete is investigated using pull out test. Two types of reinforcement, glass FRP rods and Hybrid wire FRP rods of $8 \mathrm{~mm}, 10 \mathrm{~mm}$ and $12 \mathrm{~mm}$ diameter were used in this study. Several relevant factors have been considered in this study including concrete compressive strength and the rod diameter among other parameters. It has been concluded that the bond strength increased by increasing in concrete compressive strength while the bond strength between the surrounding concrete and the hybrid wires FRP rods decreased with the increasing of the rod diameter and the increasing of embedded length from rods. Eventually, it has been shown that ribbing of rods surface has a significant enhancement on the bond strength.

Keywords: Fibre-Reinforced Polymers; Hybrid rods; Glass fibre reinforced; Pull out test; bond behaviour.

Cite this Article: Mamdouh Sayed Abdelbaqi, Mohaseb Ahmed Abozied, Mohamed Ahmed Saifeldeen, Hossameldeen Mohamed, Omar Ahmed Farghal and Abd El Rahman Megahid Ahmed, Evaluation of the Local Manufacturing and Bond Behaviour of GFRP Rods Hybridized with Steel Wires for Concrete Reinforcement. International Journal of Civil Engineering and Technology, 11(5), 2020, pp. 11-27. https://iaeme.com/Home/issue/IJCIET?Volume=11\&Issue=5

\section{INTRODUCTION}

One of the reasons for shortening life for reinforced concrete structures is steel corrosion see Figure 1 [1], various methods were suggested to overcome this big problem such as epoxy coating and high-performance concrete are used [2], but it was useless over time. When some suggested treating the corrosion of reinforced concrete structures, it was found that this was also subjected to high cost over time [3]. One of the most affordable alternatives to steel rods is using FRP rod instead it, to overcome the corrosion problem of structural steel.

FRP can provide high strength and good resistance to corrosion compared with reinforcing iron for concrete structures, Recently, FRP rods have been relied on in hostile environments that attack and cause corrosion of steel, such as sea water. At present, there are many active researches in the field of FRP where FRP structural reinforcements are being made for concrete structures in (KICT 2012)[4].

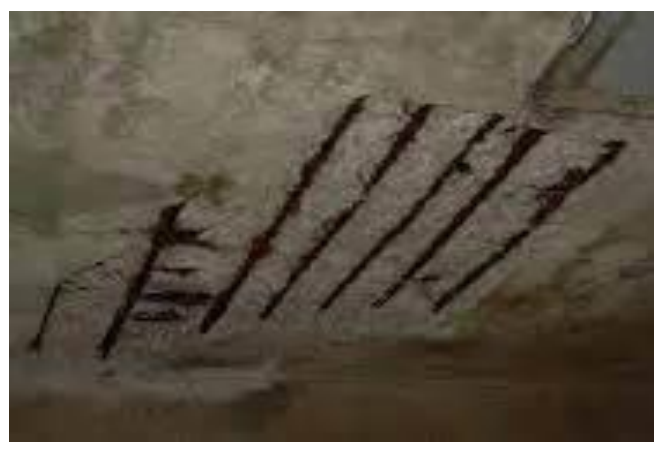

Figure 1 Corrosion of Steel Rods

Unfortunately, the disadvantage of using FRP rods is the low modulus of elasticity which led to increase in deformations. while the using of steel rods led to give a high ductility, [5]. Hybrid wire rods was a good alternative to steel rods, because it is rust proof, a good 
alternative to fibre also to overcome the limitations of FRP rods such as cost and elastic modulus. Hybrid rods were manufactured by using E-glass fibres and unsaturated polyester resins incorporated with steel wires as shown Figure 2, [1].

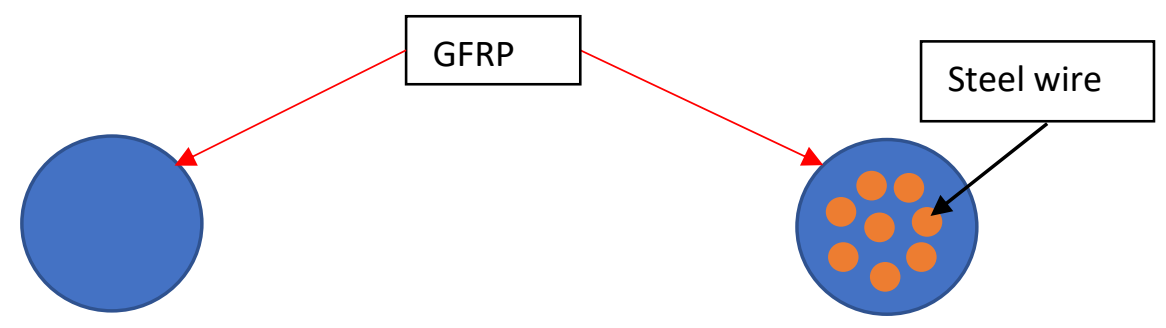

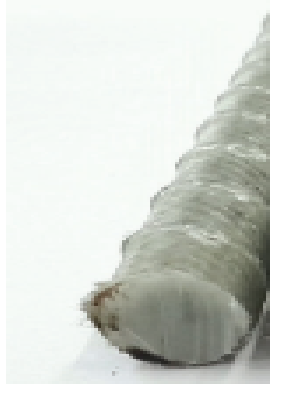

(a)

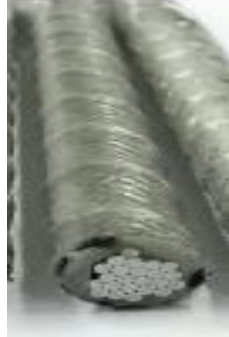

(b)

Figure 2 General Frame of the Rods

Type (A) (GFRP Rod); Type (B) (GFRP Rods with Steel Wires into it)

There are plentiful modes used to manufacture FRP materials used for structural engineering applications, for example, pultrusion, wet lay-up, and injection molding. Pultrusion is the typical operation used to found straight rods. It is an ideal process for products with a constant cross section see Figure 3, [6] and [7].

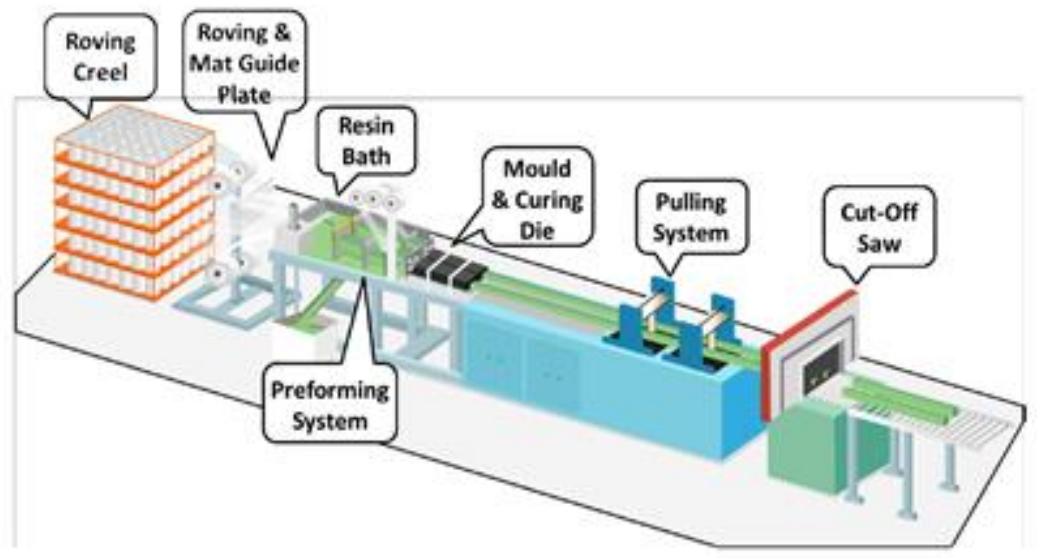

Figure 3 Pultrusion Process, [7]

The process begins with the raw bres stored in small spools called rovings which are kept on metal racks called creels. Bres travels through a bath of polymeric resins, allowing for maximum impregnation of the bres into the resin. Upon exiting the resin bath, the bres travels through a preforming system that continues to align the individual bres while removing excess resin. The wet bres are then pulled through a heated die which molds the section and cures the resin. As a result of the elevated temperatures, the composite shrinks and separates 
from the internal walls of the die and exits as the nished product. The cured composite is typically pulled by means of urethane pads using a caterpillar belt. A cut-off saw is positioned at the end of the assembly to create products of set lengths as shown as in Figure 3.

O. CHAALLA and B.Benmokrane [8], his method is similar to this method, which was used to manufacture of FRP but more primitive.

Park et al. [1], studied the manufacture of three types of hybrid rods (Type A, GFRP rod without hybridization, Type B, C and D are respectively the first type GFRP with steel core, the second type GFRP rod with steel wires (diameter $2 \mathrm{~mm}$ ), and the third type GFRP with deformed steel rod.), Figure 4 show a summarize of fabrication of FRP hybrid-wire rods and its cross section.

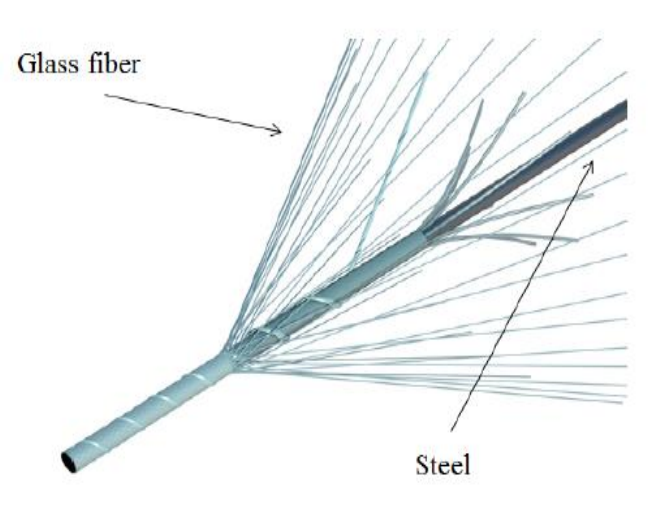

(A) Detailed View of Braiding

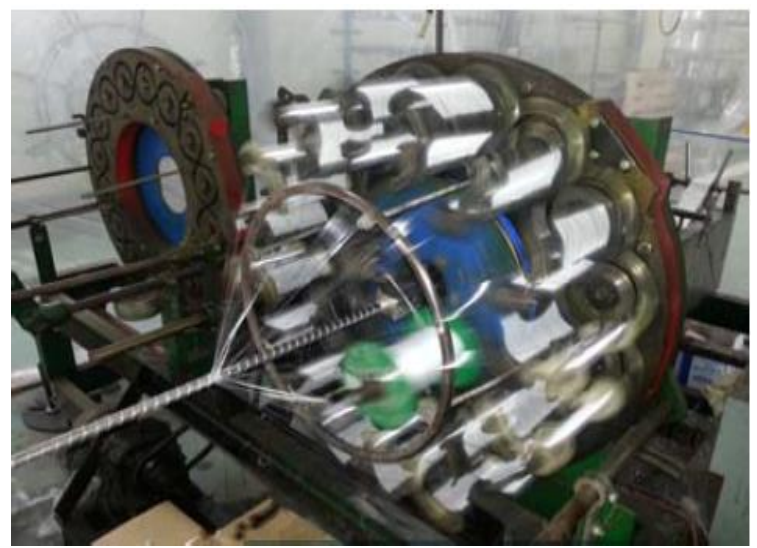

(B) Pultrusion While Bradding

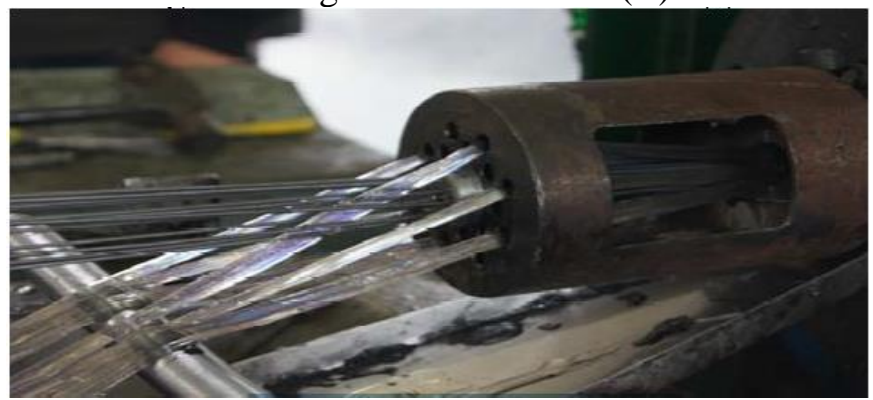

(C) Type C Manufacture Device

Figure 4 Fabricating Method For FRP Wires Rods [1], [9] And [10]

lee, et, al (2017) [11]studied the bond behavior of GFRP rods in high-strength concrete by using two rods diameter (19 and 25) mm and three patches of concrete strength $(20,40$ and $60 \mathrm{MPa}$ ). It was clear from the results found in the discus that with rise the value of the concrete compressive strength, they noted that the bond strength was raised also, bond strength was decreased with the increasing of the rod diameter. In the American code (ACI 2011)[12] almost the same results are indicated.

Juan Pablo et al, (2012) [13], Studied the change in the embedded length of the FRP rods in the surrounding concrete.

They used rods with diameter of $16 \mathrm{~mm}$ and with the embedded parts of rods were of different whether 5 or 10 times of the diameter of the rods used.

The outer surface of the FRP rods was influential on the bond behaviour of the rods with the difference in embedded length. It is clearly that the bond strength was conformable when the outer surface of the rod was smooth with the difference of the embedded length. 
Mamdouh Sayed Abdelbaqi, Mohaseb Ahmed Abozied, Mohamed Ahmed Saifeldeen,

Hossameldeen Mohamed, Omar Ahmed Farghal and Abd El Rahman Megahid Ahmed

It is noted that the bond behaviour for the shorter length is twice that of the longer length, in the surfaces course with sand to increase cohesion with the surrounding concrete. This could be explained by taking into account that in tall lengths, the nonlinear distribution of bond stresses along the FRP rods is more clearly.

One of the main objectives of the research in question is to clarify the method of manufacturing locally for glass FRP and hybrid wirs FRP rod (new type), as well as to study the behaviour of bond for new type and GFRP rods with the concrete surrounding them.

\section{EXPERIMENTAL WORK}

\subsection{Materials}

Local natural sand and coarse aggregate, ordinary Portland cement, water, silica fume and superplasticizer (Sikament R2008) were used in this experimental program. Glass fibre reinforced polymer (GFRP) rods and hybrid-wire rods, which manufactured in laboratory for the purpose of this study, were used as main longitudinal reinforcement. Mild steel reinforcement was used as shear and compression reinforcement. The following sections present the most relevant characteristics of used materials.

\subsubsection{Concrete Admixture}

Three different concrete batches with target cube compressive strengths of 250, 400 and 500 $\mathrm{kg} / \mathrm{cm}^{2}$ were used for casting the beams. The concrete mixes were prepared in the laboratory according to the mix proportions presented in Table 1Next sections provide a full description of these materials along with their main mechanical properties.

Table 1 Rate of Concrete Blend Used in Shaping the Tested Sample

\begin{tabular}{|c|c|c|c|c|c|c|c|c|c|}
\hline $\begin{array}{c}\text { Target } \\
F_{c u} \text { at } 28 \\
\text { days } \\
(\mathrm{MPa})\end{array}$ & $\begin{array}{c}\text { Mean } \\
F_{c u} \text { at } \\
28 \text { days } \\
(\mathrm{MPa})\end{array}$ & $\stackrel{\bigcup}{3}$ & 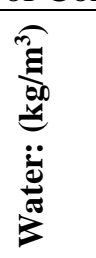 & 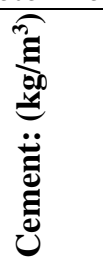 & 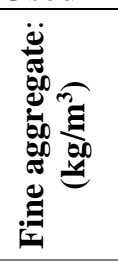 & 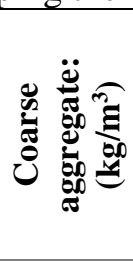 & 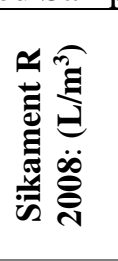 & 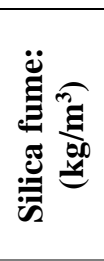 & 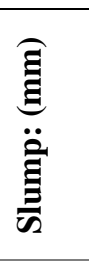 \\
\hline $\mathrm{C} 25$ & 27.3 & 0.5 & 174 & 350 & 635 & 1296 & ------ & ----- & 6.3 \\
\hline C40 & 42 & 0.36 & 162 & 450 & 565 & 1215 & 8 & 55 & 4.8 \\
\hline C60 & 61.7 & 0.304 & 152 & 500 & 498 & 1196 & 11 & 70 & 5.2 \\
\hline
\end{tabular}

\subsubsection{Cement}

Ordinary Portland cement with a strength of $52.5 \mathrm{~N}$ was used for types tested. The mechanical properties of the used cement agree with the Egyptian standards (4756-1 /2007)[14]. The properties of the used Assiut Cement-Cemex are applied in the Table 2.

Table 2 Test results of Ordinary Portland Cement (Assiut Cement-Cemex).

\begin{tabular}{lcc}
\hline \multicolumn{1}{c}{ Property } & Test Values & Allowable value [15]. \\
\hline \% of Retained on Sieve No. 170 & $1 \%$ & Maximum 10\% \\
Initial setting times (min) & $100 \mathrm{~min}$ & Minimum 45 min \\
Final setting times (min) & $150 \mathrm{~min}$ & Maximum $600 \mathrm{~min}$ \\
Expansion of paste by Le-Chatelier Apparatus & $2 \mathrm{~mm}$ & Maximum $10 \mathrm{~mm}$ \\
Mortar compressive $\quad 3$ days & $20 \mathrm{~N} / \mathrm{mm} 2$ & Minimum $18 \mathrm{~N} / \mathrm{mm} 2$ \\
strength $(\mathrm{MPa})$ & $55 \mathrm{~N} / \mathrm{mm} 2$ & Minimum $52.5 \mathrm{~N} / \mathrm{mm} 2$
\end{tabular}

\subsubsection{Aggregate}

Local sand obtained from Mangabad city, Assiut, Egypt was used as fine aggregate. The specific gravity, volume weight and fineness modulus were found to be $2.63,16.1 \mathrm{kN} / \mathrm{m}^{3}$ and 
2.71, respectively. In order to ensure the cleanliness of the used sand, the sand was washed and dried in open area before used. Also, in according to Egyptian code (ECP 203-2007) [15] , the used sand is screened in order to remove all fine sand. The result of the sieve analysis carried out is shown in Figure 5.

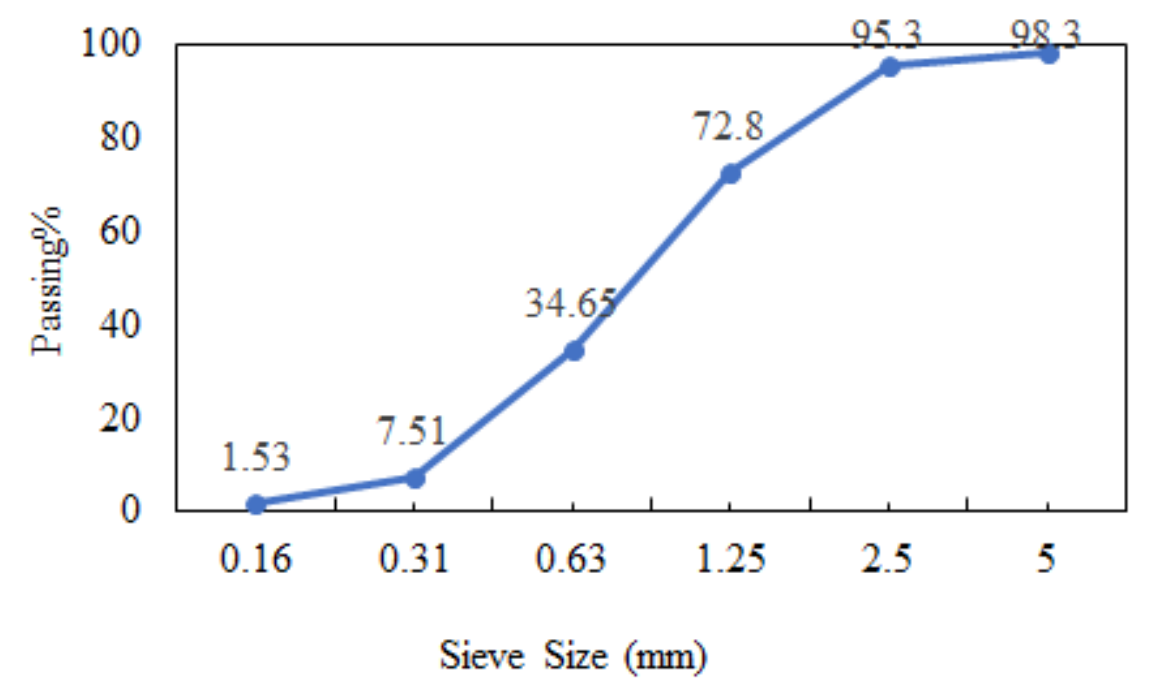

Figure 5 Sieve Analysis of the Fine Aggregate

Compressive strength of concrete depends on the consistency between the cement paste and the used aggregate. Coarse aggregate plays a key role in the resulting compressive strength, therefore, for the sake of high-quality concrete admixtures, a clean solid coarse aggregate was used. The coarse aggregate particles were selected to be free from any chemical substances or any unwanted attached particles such as clay or any kind of fine material. Also, the used aggregate has a suitable surface and shape which help to obtain the required strength of concrete as shown in the attached image to the sieve analysis of coarse aggregate in Figure 6. The main characteristics of the used gravel are presented in Table 3.

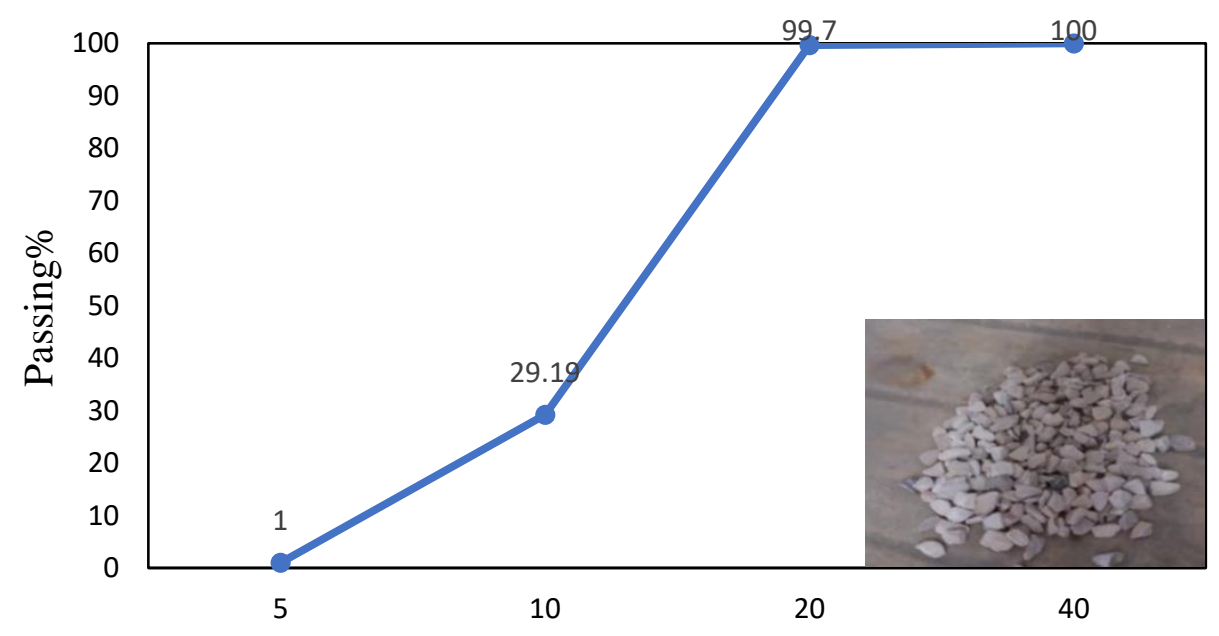

Sieve Size (mm)

Figure 6 Sieve Analysis of the Coarse Aggregate 
Mamdouh Sayed Abdelbaqi, Mohaseb Ahmed Abozied, Mohamed Ahmed Saifeldeen,

Hossameldeen Mohamed, Omar Ahmed Farghal and Abd El Rahman Megahid Ahmed

Table 3 Characteristics of Coarse Aggregate

\begin{tabular}{lc}
\hline \multicolumn{1}{c}{ Property } & Value \\
\hline Maximum nominal size $(\mathrm{mm})$ & 20 \\
Dry volume weight $\left(\mathrm{t} / \mathrm{m}^{3}\right)$ & 1.45 \\
Specific gravity & 2.57 \\
Percentage of absorption & $0.56 \%$ \\
Aggregate crushing value & $9.4 \%$ \\
Fineness modulus & 6.7 \\
\hline
\end{tabular}

\subsubsection{Water}

Water used for both concrete mix and curing of cubes was tap water. Table 4 shows the test results of chemical analysis for the water sample.

Table 4 Chemical Analysis for the Water Sample

\begin{tabular}{ccc}
\hline Element & Value in sample & $\begin{array}{c}\text { Allowable value } \\
{[\mathbf{1 5}]}\end{array}$ \\
\hline $\mathrm{PH}$ & & $6.5-8.5$ \\
$\mathrm{TDS}(\mathrm{mg} / \mathrm{L})$ & 164 & 1200 \\
$\mathrm{~K}(\mathrm{mg} / \mathrm{L})$ & 0.215 & 0.30 \\
$\mathrm{Ca}(\mathrm{mg} / \mathrm{L})$ & 29.4 & 100 \\
$\mathrm{Cl}-(\mathrm{mg} / \mathrm{L})$ & 17 & 500 \\
$\mathrm{Mg}(\mathrm{mg} / \mathrm{L})$ & 11.56 & 250 \\
$\mathrm{Mn}(\mathrm{mg} / \mathrm{L})$ & 0.073 & 0.10 \\
$\mathrm{Fe}(\mathrm{mg} / \mathrm{L})$ & 0.34 & 5 \\
$\mathrm{So3}(\mathrm{mg} / \mathrm{L})$ & 84.12 & 300 \\
Odor & Odorless & \\
\hline
\end{tabular}

\subsubsection{Silica Fume}

In order to enhance the compressive strength, bond strength, and abrasion resistance of the concrete admixture, silica-fume has been used as additive. The silica fume produced by a Factory in Edfu, Egypt with the physical and chemical properties presented inTable 5. is used in the concrete admixture.

Table 5 Physical and Chemical Properties of Silica Fume [16]

\begin{tabular}{|c|c|c|}
\hline Property & Measured values & Limitations \\
\hline \multicolumn{3}{|c|}{ Physical properties: } \\
\hline Color & Light gray & -- \\
\hline Specific gravity & 2.15 & -- \\
\hline Bulk density $\left(\mathrm{kg} / \mathrm{cm}^{3}\right)$ & 340 & $250-450$ \\
\hline \multicolumn{3}{|c|}{ Chemical properties } \\
\hline $\mathrm{SiO} 2$ & $97 \%$ & $90 \% \min$ \\
\hline $\mathrm{C}$ & $0.5 \%$ & $1 \% \max$ \\
\hline $\mathrm{Fe} 2 \mathrm{O} 3$ & $0.5 \%$ & $1.5 \% \max$ \\
\hline $\mathrm{A} 12 \mathrm{O} 3$ & $0.2 \%$ & $1 \% \max$ \\
\hline $\mathrm{CaO}$ & $0.2 \%$ & $1 \% \max$ \\
\hline $\mathrm{MgO}$ & $0.5 \%$ & $1.5 \% \max$ \\
\hline $\mathrm{K} 2 \mathrm{O}$ & $0.5 \%$ & $1.5 \% \max$ \\
\hline $\mathrm{Na} 2 \mathrm{O}$ & $0.21 \%$ & $0.5 \% \max$ \\
\hline $\mathrm{SO} 3$ & $0.16 \%$ & $0.2 \% \max$ \\
\hline $\mathrm{Cl}$ & $<0.01 \%$ & $0.05 \% \max$ \\
\hline $\mathrm{H} 2 \mathrm{O}$ & $0.5 \%$ & $0.8 \% \max$ \\
\hline $\mathrm{PH}$ & $7.8 \%$ & $\pm 1 \% \max$ \\
\hline
\end{tabular}


Evaluation of the Local Manufacturing and Bond Behaviour of GFRP Rods Hybridized with Steel Wires for Concrete Reinforcement

\subsubsection{Super Plasticizers}

In order to enhance the workability of concrete admixture and its mechanical properties, Sikament R2008 produced by Sika company Egypt was added to the concrete admixtures with reasonable ratios (see Table 1). In addition to enhancing the workability of concrete with reduced water content $(\mathrm{w} / \mathrm{c})$ up to $25 \%$, adding Sikament R2008 to concrete admixture maximizes the strength of concrete without exposure to granular separation. All the aforementioned reasons make the use of this additive is suitable for the climate with extreme high temperature which the case for upper Egypt. The properties of Sikament R2008 are shown in Table 6.

Table 6 Properties of Sikament R2008[17]

\begin{tabular}{ll}
\hline \multicolumn{1}{c}{ Property } & \multicolumn{1}{c}{ Measured values } \\
\hline Appearance / Colors & dark brown \\
\hline Density $\left(20^{\circ} \mathrm{C}\right)$ & $1.2 \mathrm{~kg} / \mathrm{L},(\mathrm{ASTM} \mathrm{C}-494)$ \\
\hline Packaging & $\begin{array}{l}\text { Packing jacks } 5-20 \mathrm{~kg}-\text { drums } 220 \mathrm{~kg} \text {, Tank trucks possible } \\
\text { on request. }\end{array}$ \\
\hline Storage Conditions / Shelf Life & $\begin{array}{l}12 \text { months from date of production if stored properly in } \\
\text { original and unopened packaging (drums, containers) at } \\
\text { temperatures between }+5^{\circ} \mathrm{C} \text { and } 35^{\circ} \mathrm{C} \text { protect from direct } \\
\text { sunlight. }\end{array}$ \\
\hline
\end{tabular}

\subsection{GFRP and Hybrid Wires Rods}

As aforementioned that the used FRP rods either pure or hybrid were produced in the lab. The following section gives details about Fabrication of the FRP rods appended by their resulting mechanical tests.

\subsubsection{Fabrication of FRP Rods}

\subsubsection{Fabrication of FRP Rods with Heating}

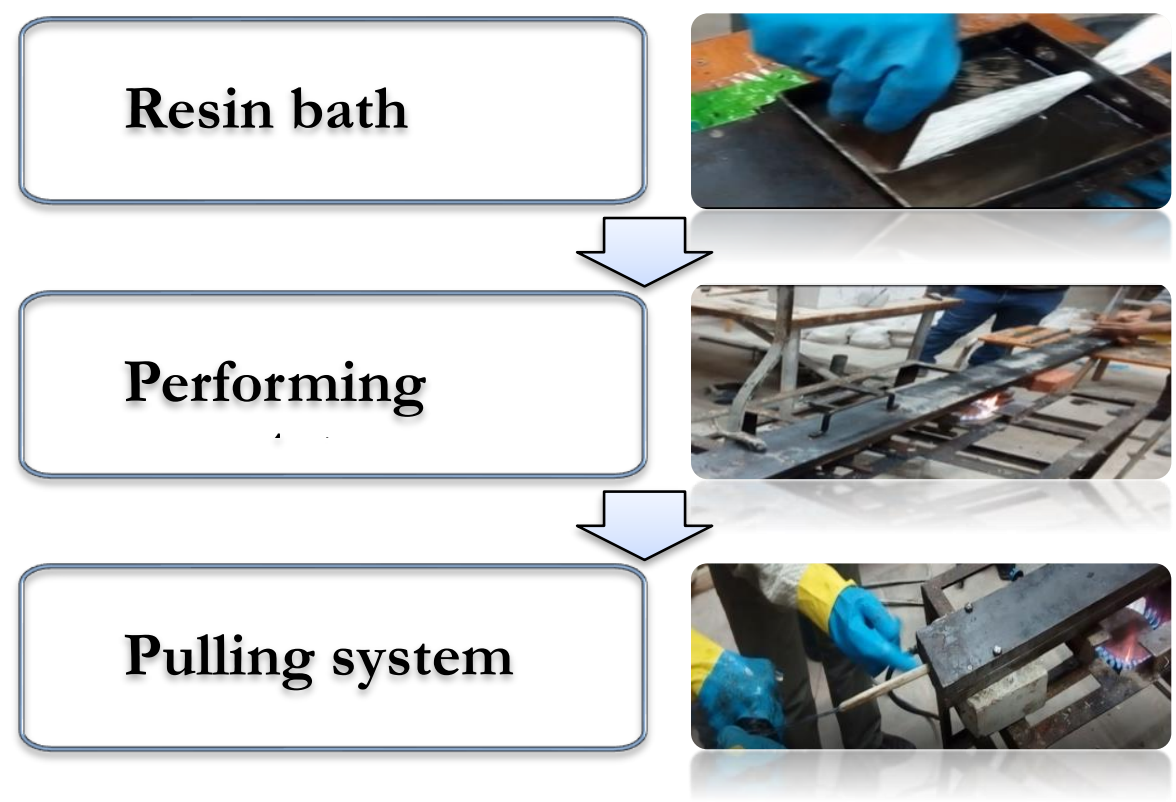

Figure 7 Pultrusion Process

The process for fabrication of FRP at laboratory has three main stages as shown in Figure 7 which begins with resin bath. During the resin bath, the fibres are moved through a bath of polymeric resins, thus allowing for maximum impregnation of the fibres into the resin. Upon 
exiting the resin bath, the fibres are moved to performing system stage where they are being removed excess resin. Eventually pulling system stage, where the wet fibres are then pulled through a heated preforming system which moulds the section and cures the resin. As a result of the elevated temperatures, the composite shrinks and separates from the internal walls of the die and exits as rod.

In this method, it is noticed that the new rods which made locally recently have a smooth surface. To improve the bond strength between GFRP rods and the reinforced concrete, a local $2 \mathrm{~mm}$ diameter of glass fibre strands helically wound around the smooth rods and pasted by (Kemapoxy 165) or use sand to make the surface rougher than it was. See Figure 8.

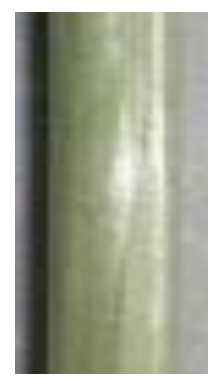

a)

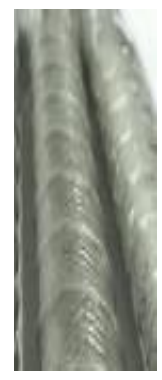

b)

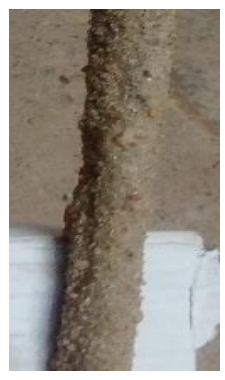

c)

Figure 8 Different Rod Surface Treatments: (A) Smooth, (B) With Deformations And (C) With Sand Coating

Also, the ribbed hybrid-wire FRP rods (steel wires incorporated with fibres) have been manufactured in laboratory for the purpose of this study. The hybrid-wire rods were manufactured by combining glass fibres with and steel wires with epoxy resin without heat using the rotary machine shown in Figure 9 (a). Steel wires are covered by glass fibres in the hybrid-wire rod to prevent the corrosion problem the steel wires were spread almost symmetrical and the concentrated was on the core of the rods and the assembly of the Wires, as shown in Figure 9 (b).

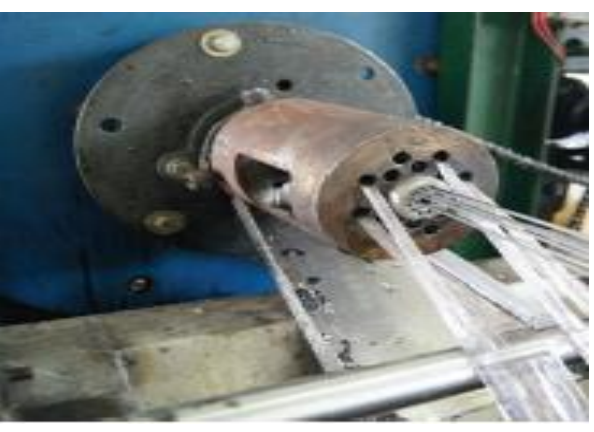

a) Manufacture Device
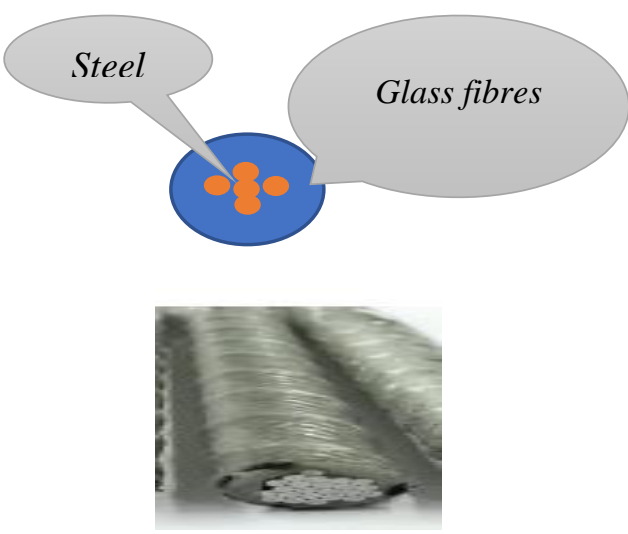

b) Hybrid Rods

Figure 9 Manufacture of Hybrid Wires Rods

\subsubsection{Fabrication of FRP rods without Heating}

The second method of manufacturing of FRP was without using heating process. Four-stage process were followed in order to reach the final product as presented in Figure 10. First, the raw fibre from glass is arranged in accordance with the required diameter. Then, resin bath stage, where the prepared fibres are placed inside the resin bath until completely saturated. 
After the Resin bath, performing system stage is stared with placing the saturated rods inside the mould for the desired diameter. Eventually, after the consolidation of the rods are removed from the mould and left in the air until completely dried and any surface is polished to remove all bumps to reach the desired diameter.

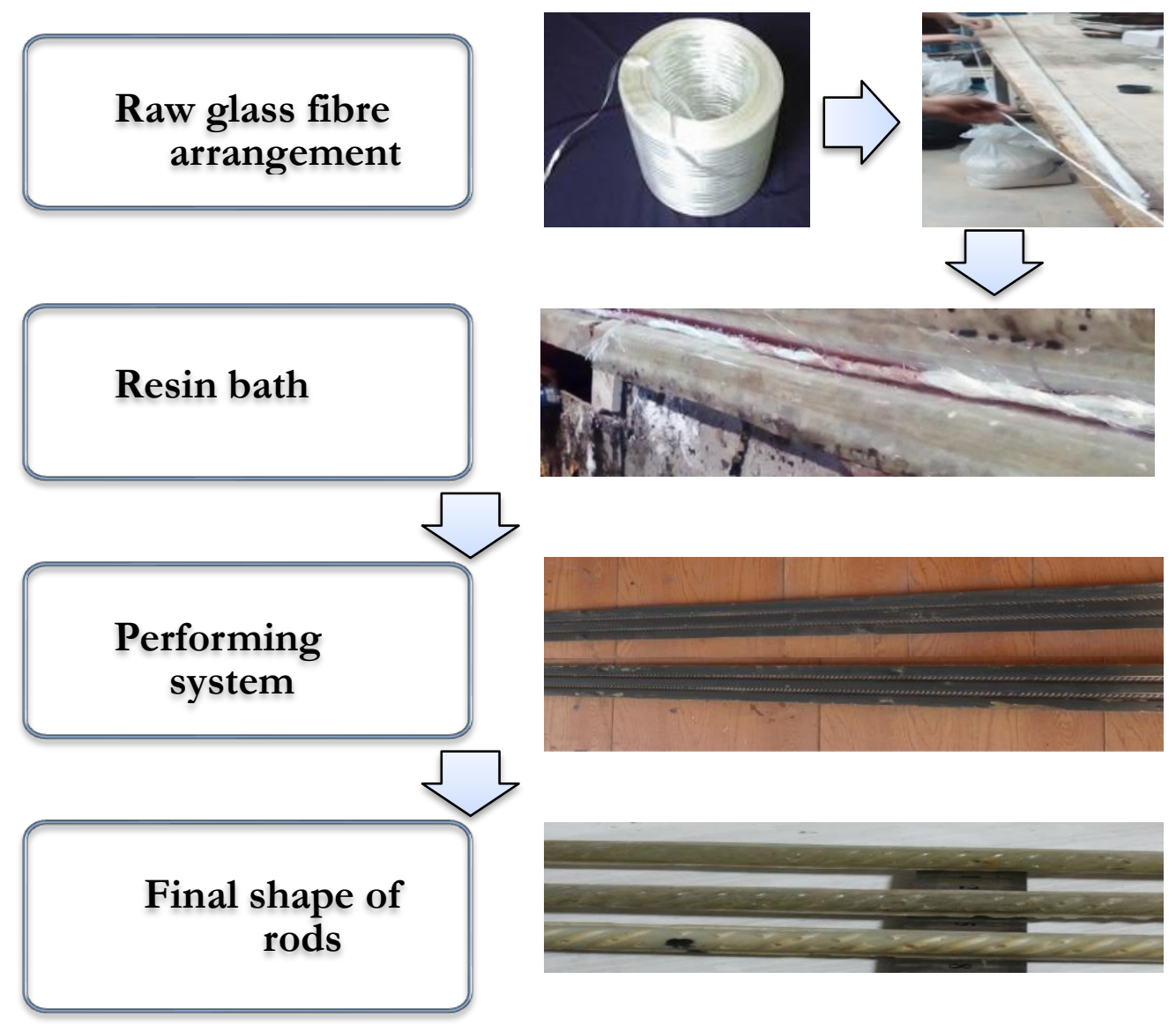

Figure 10 Process for Fabrication of FRP Rods Without Heating

\subsubsection{Mechanical Properties of Rods}

Steel and FRP rods were tested according to Egyptian code (ECP208-2005)[18], Their mechanical properties are listed in Table 7. In this article, the effect of concrete compressive strength on bonding characteristics, therefore, three value were used: 25,40 and $60 \mathrm{MPa}$. In Table 1, the different proportions of the material to obtain the desired concrete mixtures were recorded. Thirty-two cylindrical concrete specimens were prepared and tested under the pullout test, Figure 11.
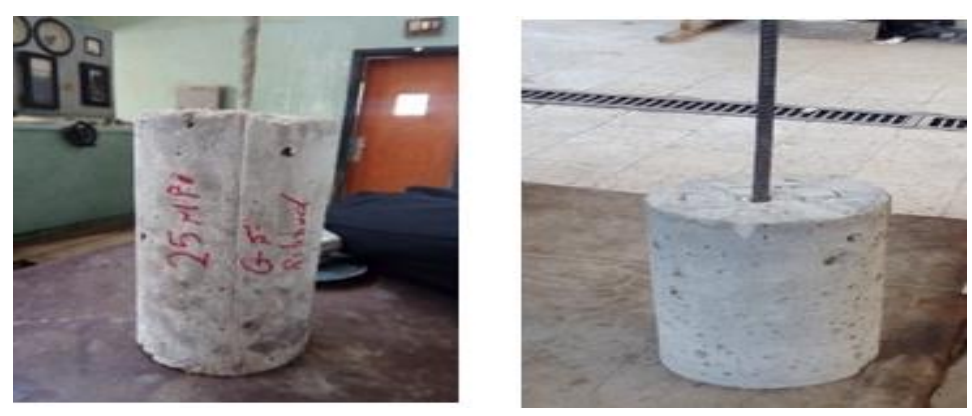

Figure 11 Cylindrical Concrete Specimens 
Mamdouh Sayed Abdelbaqi, Mohaseb Ahmed Abozied, Mohamed Ahmed Saifeldeen,

Hossameldeen Mohamed, Omar Ahmed Farghal and Abd El Rahman Megahid Ahmed

Table 7 Value Specimen as Average for The of Tensile Test of Three All Sorts

\begin{tabular}{|c|c|c|c|c|c|}
\hline 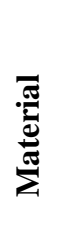 & 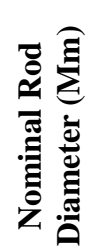 & 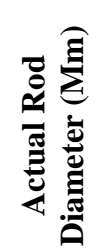 & 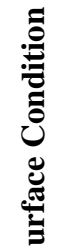 & 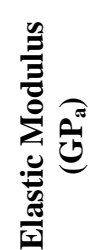 & 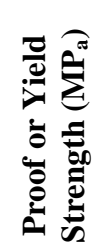 \\
\hline
\end{tabular}

\begin{tabular}{|c|c|c|c|c|c|c|}
\hline Steel & 10 & 10.1 & Ribbed & 200 & 368 & 525 \\
\hline \multirow{3}{*}{ GFRP } & 8 & 7.9 & Smooth & 44 & ----- & 1048 \\
\hline & 10 & 9.9 & $\begin{array}{l}\text { Smooth } \\
\text { Ribbed }\end{array}$ & 44 & ----- & 1128 \\
\hline & 12 & 12.01 & Smooth & 48 & ----- & 1230 \\
\hline \multirow{3}{*}{$\begin{array}{l}\text { Hybrid } \\
\text { (50\%Steel+50\% } \\
\text { GFRP) }\end{array}$} & 8 & 7.99 & Smooth & 82.5 & 610 & 923 \\
\hline & 10 & 10.02 & Ribbed & 84 & 520 & 834 \\
\hline & 12 & 11.98 & Smooth & 105 & 708 & 1120 \\
\hline
\end{tabular}

\subsubsection{Specimens}

This paper debates an experimental program in pull out test. A cylinder of $(15 \mathrm{~cm} x 30 \mathrm{~cm})$ were used for test. Table 8. Shows all test sample details.

Table 8. General details of the samples tested in this discuss

\begin{tabular}{|c|c|c|c|c|c|}
\hline Specimen & Rod type & Rod diameter (mm) & $\begin{array}{c}\text { Embedment length } \\
(\mathbf{m m})\end{array}$ & $F_{c u}\left(\mathbf{M P}_{\mathrm{a}}\right)$ & $\begin{array}{c}\text { Surface } \\
\text { condition }\end{array}$ \\
\hline G1 & \multirow{6}{*}{ GFRP } & 8 & \multirow{3}{*}{50} & \multirow{24}{*}{25} & \multirow{12}{*}{ Smooth } \\
\hline G2 & & 10 & & & \\
\hline G3 & & 12 & & & \\
\hline G4 & & 8 & \multirow{3}{*}{90} & & \\
\hline G5 & & 10 & & & \\
\hline G6 & & 12 & & & \\
\hline GS1 & \multirow{6}{*}{ Hybrid } & 8 & \multirow{3}{*}{50} & & \\
\hline GS2 & & 10 & & & \\
\hline GS3 & & 12 & & & \\
\hline GS4 & & 8 & \multirow{3}{*}{90} & & \\
\hline GS5 & & 10 & & & \\
\hline GS6 & & 12 & & & \\
\hline G7 & \multirow{6}{*}{ GFRP } & 8 & \multirow{3}{*}{$5 \mathrm{~d}$} & & \multirow{12}{*}{ Smooth } \\
\hline G8 & & 10 & & & \\
\hline G9 & & 12 & & & \\
\hline G10 & & 8 & & & \\
\hline G11 & & 10 & $10 \mathrm{~d}$ & & \\
\hline G12 & & 12 & & & \\
\hline GS7 & \multirow{6}{*}{ Hybrid } & 8 & \multirow{3}{*}{$5 \mathrm{~d}$} & & \\
\hline GS8 & & 10 & & & \\
\hline GS9 & & 12 & & & \\
\hline GS10 & & 8 & \multirow{3}{*}{$10 \mathrm{~d}$} & & \\
\hline GS11 & & 10 & & & \\
\hline GS12 & & 12 & & & \\
\hline GS13 & \multirow{6}{*}{ Hybrid } & \multirow{6}{*}{10} & \multirow{6}{*}{$10 \mathrm{~d}$} & \multirow{2}{*}{25} & Smooth \\
\hline GS14 & & & & & Ribbed \\
\hline GS15 & & & & \multirow{2}{*}{40} & Smooth \\
\hline GS16 & & & & & Ribbed \\
\hline GS17 & & & & \multirow{2}{*}{60} & Smooth \\
\hline GS18 & & & & & Ribbed \\
\hline S1 & \multirow{2}{*}{ Steel } & \multirow{2}{*}{10} & \multirow{2}{*}{$10 \mathrm{~d}$} & 40 & \multirow{2}{*}{ Ribbed } \\
\hline $\mathrm{S} 2$ & & & & 60 & \\
\hline
\end{tabular}




\subsubsection{Test Setup}

The setup for steps of the pull-out tests is shown in Figure 12 (a). The loads were put on the specimens by a $100(\mathrm{KN})$ capacity testing machine. The load was calculated by the load cell of the test machine, while the slip rods from concrete and displacement for rods were measured using two linear variable differential transformers (LVDTs) as shown in Figure 12 (b). A Data Loggers system was used to collect the test data automatically.

The value of mean bond stress expressed as the force $F$ divided by the outer surface area of the rod embedded in the Surrounding concrete. For circular cross section reinforcing rod of which the diameter is $d$, the average bond strength can be calculated by the following formula:

$$
\tau_{a v}=\frac{F}{(\Pi . d . l)}
$$

where $L$ : the embedment length of the rod. The maximum average bond stress of all sample can be expressed by Equation (1).
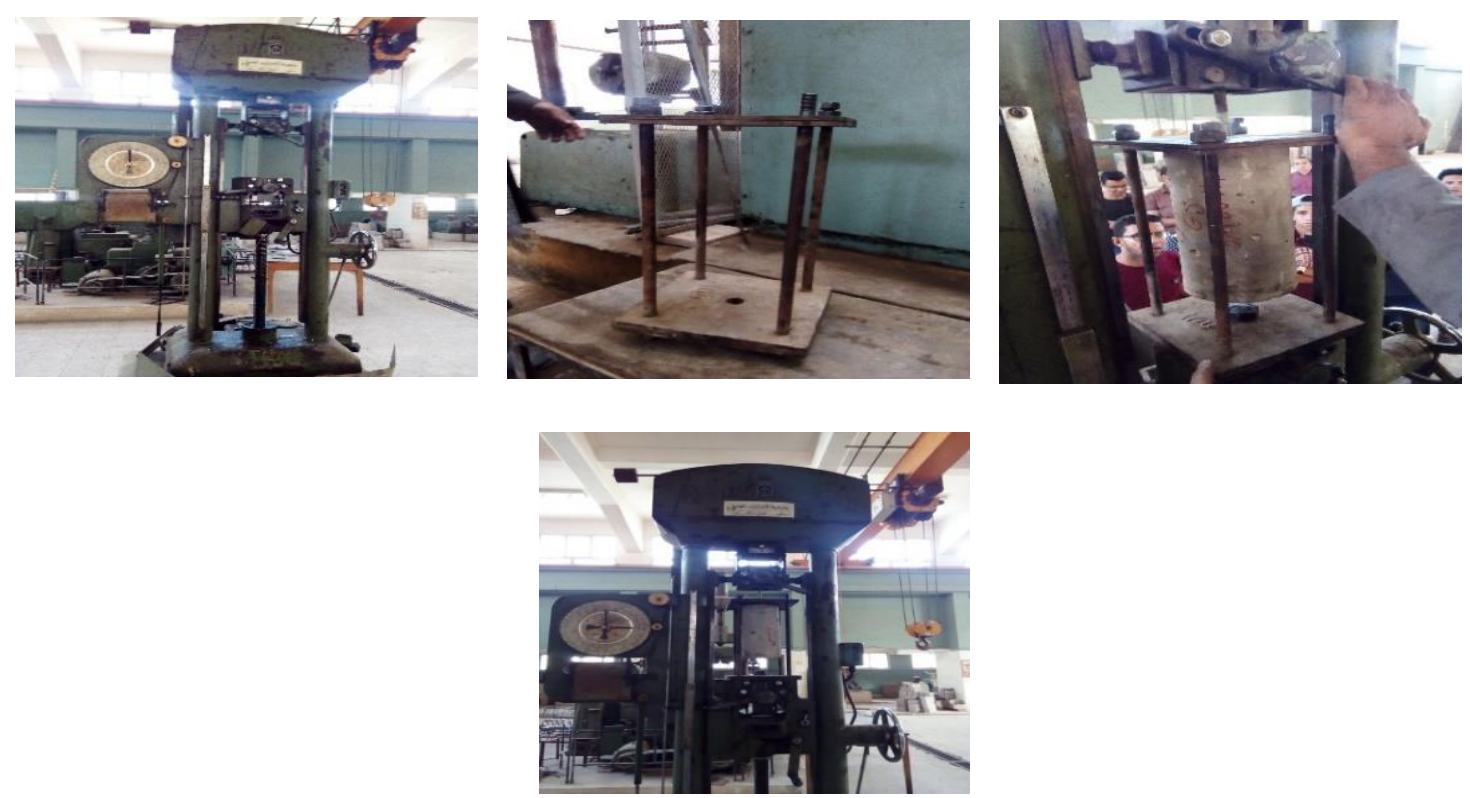

Figure 12 (a)
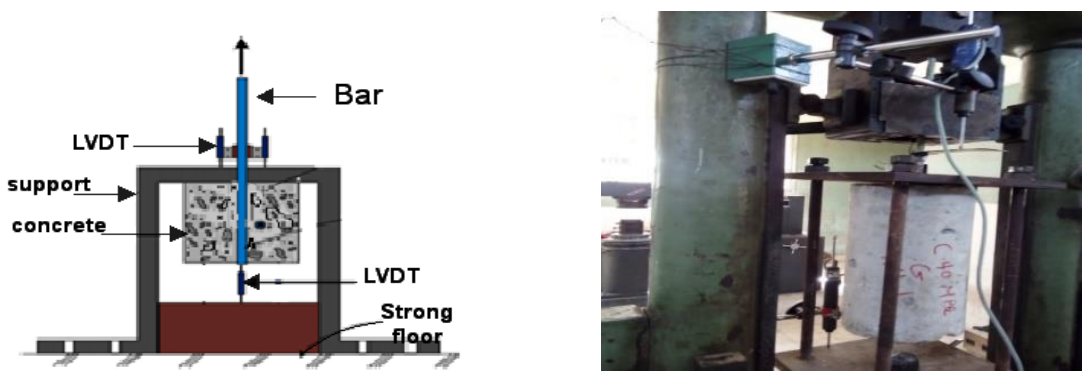

Figure 12 (b)

Figure 12 Pull-Out Test Setup 


\section{TEST OUTCOMES AND DISCUSSION}

In common, splitting and pullout failures are two predominant bond failures between rods and concrete. We studied sundry factors, like the compressive strength of the concrete, rod diameter, external surface of rods and rod embedment length.

\subsection{Load-Slip Curve}

Load slip curve for hybrid wires FRP rods and GFRP rods is shown in Figure 13. It indicates that these slips were increasing before the maximum load appearance, and indicates that the slip was small after the maximum load was occurred.

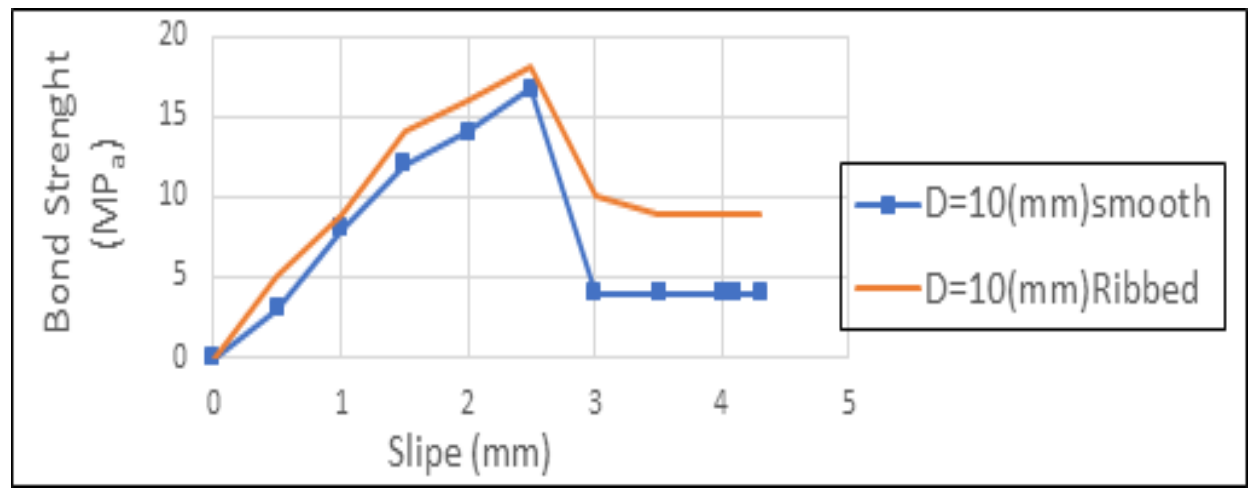

Figure 13 Bond Stress-Slip Curves

\subsection{Impact of Alteration in Diameter of Straight Rods on Bond Strength}

The medium bond strength as a function of rod diameter for $(8,10,12) \mathrm{mm}$ GFRP and hybrid wires FRP rods with concrete are plotted in Figure 14. mostly, the bond strength between rods and concrete, resort to decrease with an increase in rod diameter. The bond strength of hybrid wires FRP rods is nearly the same as in GFRP rods.

This can be demonstrated that if the diameter is larger, more bubbles are formed on its surface and increase the gap, so that the contact area between GFRP rods and concrete minimize. for this causes, the bonding strength become depress.

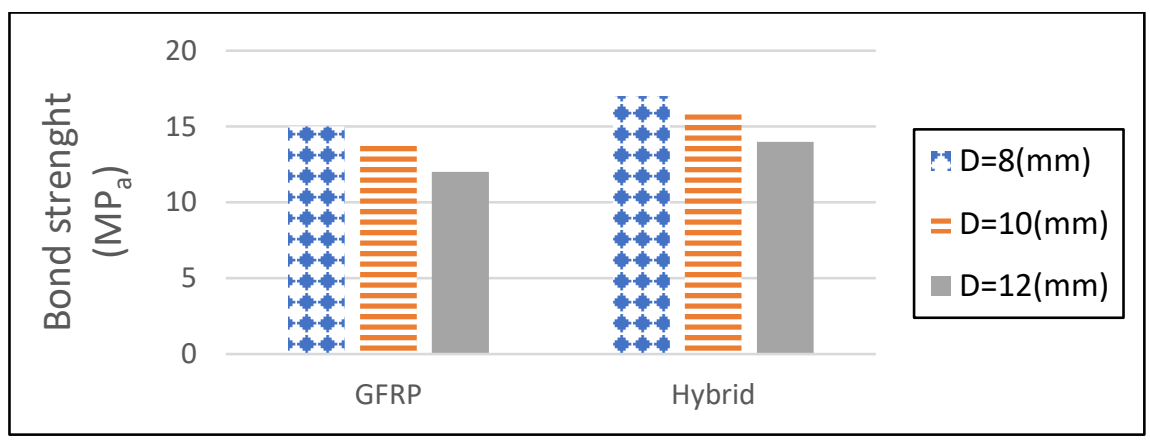

Figure 14 (a) $\mathrm{L}=50(\mathrm{~mm}), \mathrm{C} 25$ 
Evaluation of the Local Manufacturing and Bond Behaviour of GFRP Rods Hybridized with Steel Wires for Concrete Reinforcement

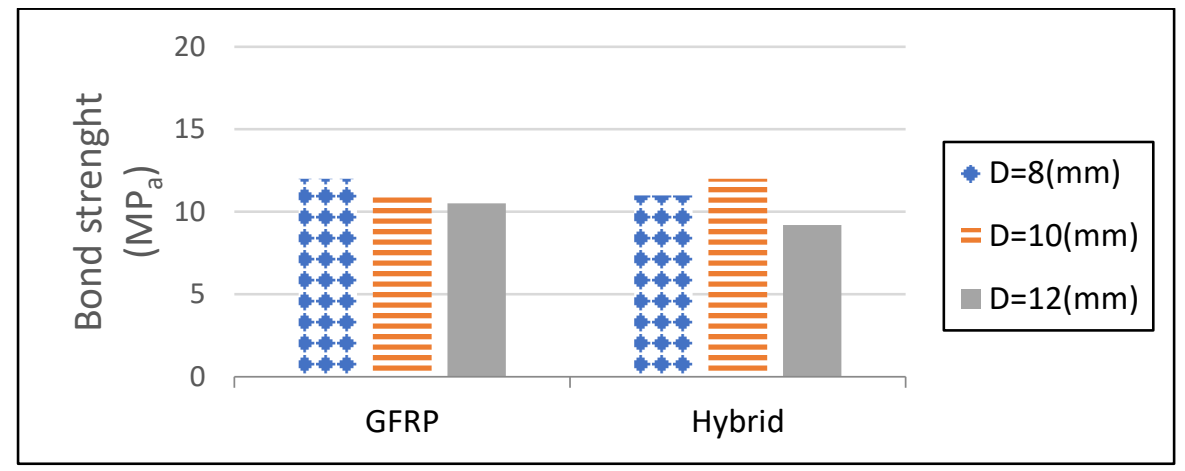

Figure 14 (b): $\mathrm{L}=90$ (mm), $\mathrm{C} 25$

Figure 14 Impact of Alteration in Diameter of Straight Rods on Bond Strength

\subsection{Impact of Alteration in Embedment Length on Bond Strength}

Figure 15 shows the mean bond strength between rods of $(8,10,12) \mathrm{mm}$ GFRP, hybrid wires FRP rods and concrete with two different Embedment length in concrete equal of 5 and 10 of the rod diameters.

We noticed that the more the embedment length in concrete, the less the strength of bond. It was also noted that the embedment length was five times the diameter, giving the strength of bond twice that is ten times the diameter See Figure 15. This is because the variability of the distribution of bond stress through the length of the tested sample of rods.

The bond strength of hybrid wires FRP rods is bigger than that of GFRP rods in case of two develop length.

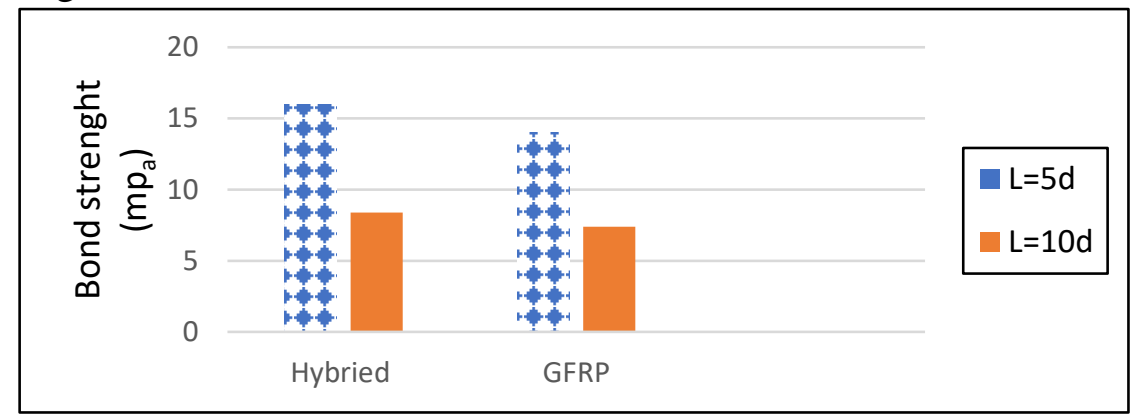

Figure 15 (a): $D=8(\mathrm{~mm}), \mathrm{C} 25$

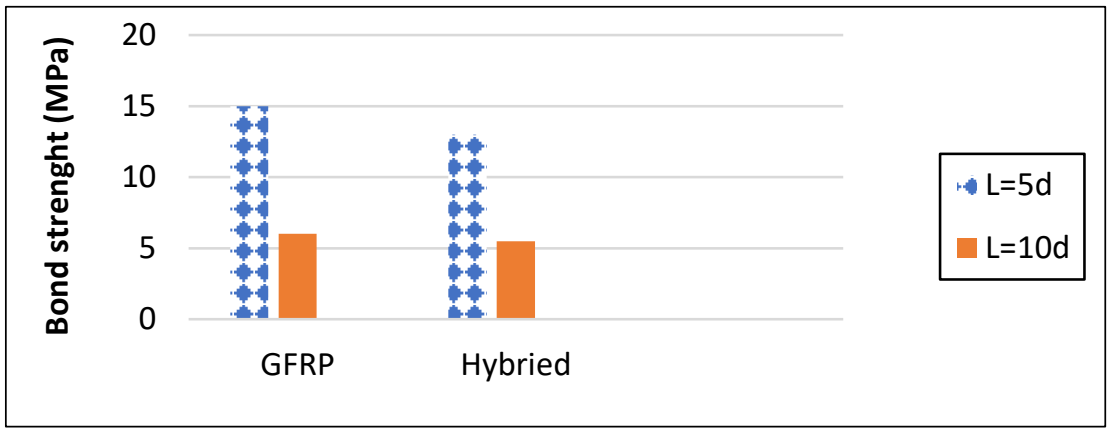

Figure 15 (b): $D=10(\mathrm{~mm}), C 25$ 
Mamdouh Sayed Abdelbaqi, Mohaseb Ahmed Abozied, Mohamed Ahmed Saifeldeen, Hossameldeen Mohamed, Omar Ahmed Farghal and Abd El Rahman Megahid Ahmed

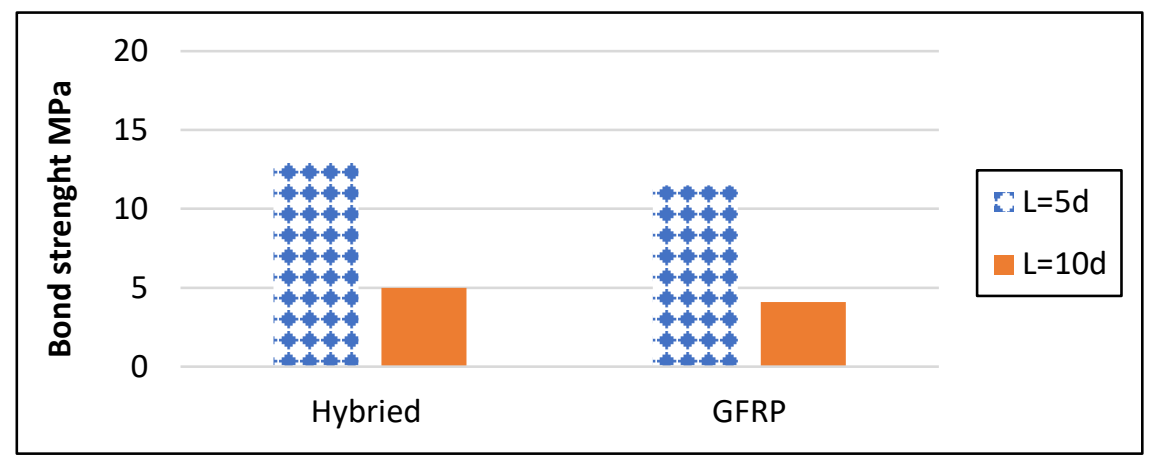

Figure 15 (c): $D=12 \mathrm{~mm}, \mathrm{C} 25$

Figure 15 Impact of Alteration in Embedment Length on Bond Strength

\subsection{Impact of the Outer Rod Surface}

Glass FRP rods offer a relatively fakir surface compared to steel rods. Figure 16 shows the breakdown of glass rods and hybrid wires FRP rods, whether the surfaces have smooth or coiled fibers around them to roughen the surfaces of these rods (ribbed rods). Also, it shows the extrinsic surface of the rod was peeled off. Pull-out failure mostly happens when the tensile strength of a bonded rod exceeds the shear strength between the rod and the surrounding concrete.

A pullout failure mode without splitting the cover occurs in most samples when they have enough cover thickness. The ribs could decrease the shear strength to pull out the rod and Smooth rods exhibited more slip than ribbed rods after reaching the maximum load.
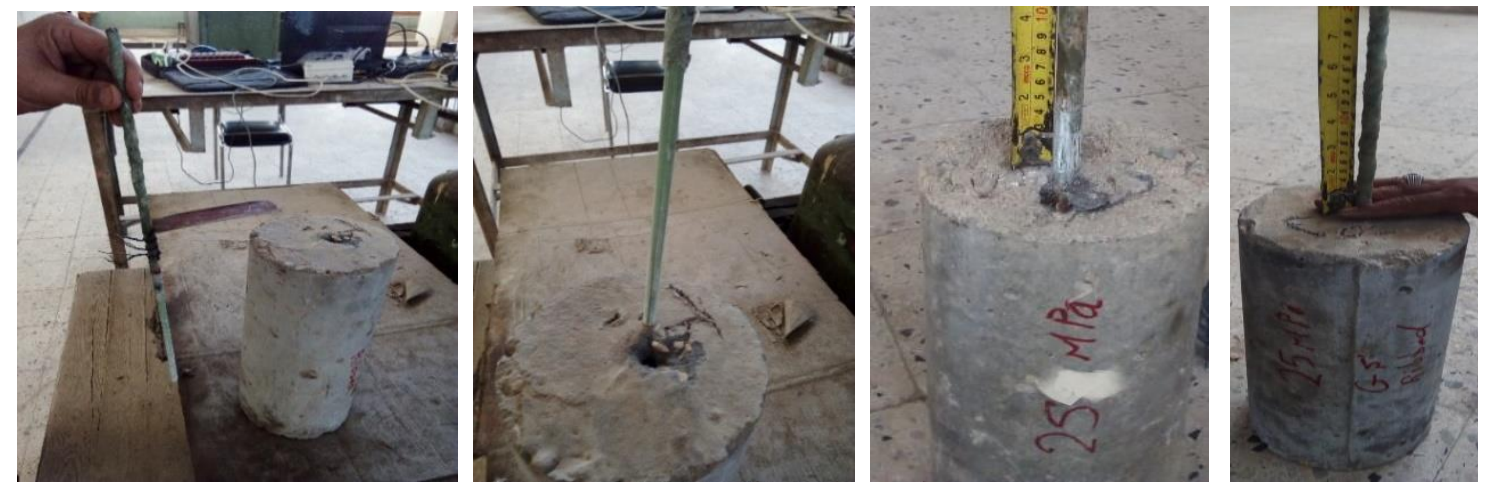

Figure 16 Bond failure mode

\subsection{Impact of Alteration in Compressive Strength on Bond Strength}

Figure 17 are plotted between different concrete compressive strength and the bond strength of the examined rods under the same experimental conditions (except for surface). For the traditional steel rods, the bond strength for the examined rods increased linearly with increasing in different concrete compressive strength, and the average of increasing was comparatively large. The bond strength the examined rods are increased by increasing different studied concrete compressive strength from $25 \mathrm{MPa}$ to $60 \mathrm{MPa}$. The bond strength in case of the steel rods was larger than the smoothed FRP rods by $30 \%$, while the ribbed rods increased the bond strength by $13 \%$ comparing to the smoothed rods. 
Evaluation of the Local Manufacturing and Bond Behaviour of GFRP Rods Hybridized with Steel Wires for Concrete Reinforcement

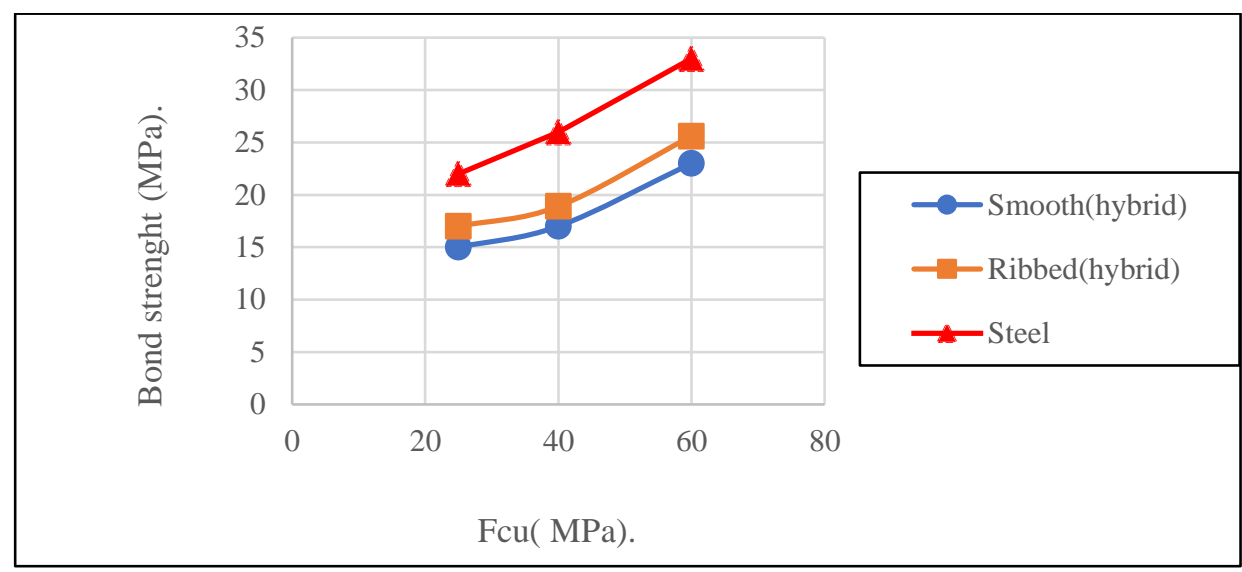

Figure 17 Impact of Alteration in Compressive Strength on Bond Strength, D=10 (mm), L=50 (mm)

\section{CONCLUSION}

The results of a tentative program to debate the bond stress behaviour of GFRP and hybrid wires FRP rods in Surrounding concrete have been presented and discussed. Thirty-two specimens were tested under the pull-out test and the conclusions summarized as follows: -

- Hybrid wires FRP rod exhibited excellent bond strength than GFRP rods in all rod's conditions. The bond strength of all the examined rods decreased as the rod diameter increased. The bond strength of hybrid wires FRP rods is the very nearly as in GFRP rods.

- The bonding strength of examined rod and concrete decreases with the increase of the bonding length. for the long length from test rods the bond strength was roughly half the small length for the examined types.

- For the steel rods examined with increase of concrete compressive strength the bond strength also increased usually, the increasing was bigger than the increasing in the FRP rods by $30 \%$. The bond strength in both of FRP types was almost Similar.

- The ribs could decrease the shear strength to pull out the rod and Smooth rods exhibited more slip than ribbed rods after reaching the maximum load.

\section{REFERENCES}

[1] K. Park, H. Kim, Y. You, S. Lee, and D. Seo, "Hybrid FRP Reinforcing Bars For Concrete Structures," 4th Asia-Pacific Conf. FRP Struct., no. December, Melbourne, Australia, p. 6, 2013.

[2] B. Saikia, J. Thomas, A. Ramaswamy, and K. S. N. Rao, "Performance of hybrid rebars as longitudinal reinforcement in normal strength concrete," Mater. Struct., vol. 38, no. 10, pp. 857-864, 2005.

[3] Z. Achillides, "Bond behaviour of FRP bars in concrete.," University of Sheffield, 1998.

[4] Korea Institute of Construction Technology (KICT). (2012), "A Proposal for The Development of a Hybrid FRP Reinforcing Bar for Waterfront Structures," in KICT Report 2012-050. Korea,

[5] J. R. Yost, S. P. Gross, and D. W. Dinehart, "Shear strength of normal strength concrete beams reinforced with deformed GFRP bars," J. Compos. Constr., vol. 5, no. 4, pp. 268275, 2001. 
Mamdouh Sayed Abdelbaqi, Mohaseb Ahmed Abozied, Mohamed Ahmed Saifeldeen, Hossameldeen Mohamed, Omar Ahmed Farghal and Abd El Rahman Megahid Ahmed

[6] J. Stoner, "Finite element modelling of GFRP reinforced concrete beams," University of Waterloo, 2015.

[7] "Unicomposite Technology (2014). Pultrusion process. Retrieved September 5, 2014 from http://www.unicomposite.com/." .

[8] O. Chaallal and B. Benmokrane, "Physical and mechanical performance of an innovative glass-fiber-reinforced plastic rod for concrete and grouted anchorages," Can. J. Civ. Eng., vol. 20, no. 2, pp. 254-268, 1993.

[9] D.-W. Seo, K.-T. Park, Y.-J. You, and S.-Y. Lee, "Experimental investigation for tensile performance of GFRP-steel hybridized rebar," Adv. Mater. Sci. Eng., vol. 2016, pp. 1-12, 2016.

[10] D. Seo, K. Park, Y. You, and J. Hwang, "Evaluation for Tensile Performance of Recently Developed FRP Hybrid Bars,” Int. J. Emerg. Technol. Adv. Eng., vol. 4, no. 6, pp. 631637, 2014.

[11] J.-Y. Lee, A.-R. Lim, J. Kim, and J. Kim, "Bond behaviour of GFRP bars in high-strength concrete: bar diameter effect," Mag. Concr. Res., vol. 69, no. 11, pp. 541-554, 2017, doi: 10.1680/jmacr.15.00403.

[12] A. C. I. (American C. Institute), "Building code requirements for structural concrete and commentary." 2011.

[13] J. P. M. Arias, A. Vazquez, and M. M. Escobar, "Use of sand coating to improve bonding between GFRP bars and concrete," J. Compos. Mater., vol. 46, no. 18, pp. 2271-2278, 2012, doi: 10.1177/0021998311431994.

[14] E. S. Specifications, "Composition, specifications and conformity criteria for common cements, Part 1," 2007.

[15] ECP, "Egyptian Code of Practice for Concrete Structures, HBRC," Arab. Cairo, Egypt, 2007.

[16] “The Egyptian Chemical Industries (kima), an Egyptian Company.Address:Kima, Edfu, Aswan, Egypt." .

[17] "Sika Company Is an Egyptian Company, Whose Address Is the First Industrial Zone, El Obour, Qalyubia, Egypt."

[18] "Egyptian Code of Practice for Design and Construction for FRP Reinforced Concrete Structures, (ECP208-2005), Housing and Building National Research Center, Giza, Egypt." 